\title{
On Mann-type iteration method for a family of hemicontractive mappings in Hilbert spaces
}

Nawab Hussain ${ }^{1}$, Ljubomir B Ćirić2 ${ }^{2}$ Yeol Je Cho ${ }^{3,4}$ and Arif Rafiq ${ }^{5 *}$

"Correspondence:

aarafiq@gmail.com

${ }^{5}$ Hajvery University, 43-52 Industrial

Area Gulberg-III, Lahore, Pakistan

Full list of author information is

available at the end of the article

\begin{abstract}
Let $K$ be a compact convex subset of a real Hilbert space $H$ and $T_{i}: K \rightarrow K$, $i=1,2, \ldots, k$, be a family of continuous hemicontractive mappings. Let $\alpha_{n}, \beta_{n}^{i} \in[0,1]$ be such that $\alpha_{n}+\sum_{i=1}^{k} \beta_{n}^{i}=1$ and satisfying $\left\{\alpha_{n}\right\}, \beta_{n}^{i} \subset[\delta, 1-\delta]$ for some $\delta \in(0,1)$, $i=1,2, \ldots, k$. For arbitrary $x_{0} \in K$, define the sequence $\left\{x_{n}\right\}$ by (1.9) see below, then $\left\{x_{n}\right\}$ converges strongly to a common fixed point in $\bigcap_{i=1}^{k} F\left(T_{i}\right) \neq \emptyset$.

MSC: Primary 05C38; 15A15; secondary 05A15; 15A18
\end{abstract}

Keywords: Hilbert space; Mann-type iteration method; pseudocontractive mapping; hemicontractive mapping; continuous mappings; Lipschitzian mapping

\section{Introduction}

Let $H$ be a Hilbert space. A mapping $T: H \rightarrow H$ is said to be pseudocontractive (see [1, 2]) if

$$
\|T x-T y\|^{2} \leq\|x-y\|^{2}+\|(I-T) x-(I-T) y\|^{2}
$$

for all $x, y \in H$ and $T$ is said to be strongly pseudocontractive if there exists $k \in(0,1)$ such that

$$
\|T x-T y\|^{2} \leq\|x-y\|^{2}+k\|(I-T) x-(I-T) y\|^{2}
$$

for all $x, y \in H$.

Let $F(T):=\{x \in H: T x=x\}$ and $K$ be a nonempty subset of $H$. A mapping $T: K \rightarrow K$ is said to be hemicontractive if $F(T) \neq \emptyset$ and

$$
\left\|T x-x^{*}\right\|^{2} \leq\left\|x-x^{*}\right\|^{2}+\|x-T x\|^{2}
$$

for all $x \in H$ and $x^{*} \in F(T)$. It is easy to see that the class of pseudocontractive mappings with fixed points is a subclass of the class of hemicontractive mappings.

The following example, due to Rhoades [3], shows that the inclusion is proper. For any $x \in[0,1]$, define a mapping $T:[0,1] \rightarrow[0,1]$ by $T x=\left(1-x^{\frac{2}{3}}\right)^{\frac{3}{2}}$. It is shown in $[4]$ that $T$ is not Lipschitz and so $T$ cannot be nonexpansive. A straightforward computation (see [5])

\section{Springer}

(c) 2013 Hussain et al:; licensee Springer. This is an Open Access article distributed under the terms of the Creative Commons Attribution License (http://creativecommons.org/licenses/by/2.0), which permits unrestricted use, distribution, and reproduction in any medium, provided the original work is properly cited. 
shows that $T$ is pseudocontractive. For the importance of fixed points of pseudocontractive mappings, the reader may refer to [1].

In the last ten years or so, numerous papers have been published on the iterative approximation of fixed points of Lipschitz strongly pseudocontractive (and, correspondingly, Lipschitz strongly accretive) mappings using the Mann iteration process (see, for example, [6]). The results which were known only in Hilbert spaces and only for Lipschitz mappings have been extended to more general Banach spaces (see [3-5, 7-33]) and the references cited therein).

In 1974, Ishikawa [34] introduced an iteration process which, in some sense, is more general than Mann iteration and which converges, under this setting, to a fixed point of $T$. He proved the following theorem.

Theorem 1.1 If $K$ is a compact convex subset of a Hilbert space $H, T: K \mapsto K$ is a Lipschitzian pseudocontractive mapping and $x_{0}$ is any point in $K$, then the sequence $\left\{x_{n}\right\}$ converges strongly to a fixed point of $T$, where $x_{n}$ is defined iteratively by

$$
\left\{\begin{array}{l}
x_{n+1}=\left(1-\alpha_{n}\right) x_{n}+\alpha_{n} T y_{n} \\
y_{n}=\left(1-\beta_{n}\right) x_{n}+\beta_{n} T x_{n}
\end{array}\right.
$$

for each $n \geq 0$, where $\left\{\alpha_{n}\right\},\left\{\beta_{n}\right\}$ are the sequences of positive numbers satisfying the following conditions:

(a) $0 \leq \alpha_{n} \leq \beta_{n}<1$;

(b) $\lim _{n \rightarrow \infty} \beta_{n}=0$;

(c) $\sum_{n \geq 0} \alpha_{n} \beta_{n}=\infty$.

In [35], Qihou extended Theorem 1.1 to a slightly more general class of Lipschitz hemicontractive mappings and, in [25], Reich proved, under the setting of Theorem 1.1, the convergence of the recursion formula (1.3) to a fixed point of $T$, when $T$ is a continuous hemicontractive mapping, under an additional hypothesis that the number of fixed points of $T$ is finite. The iteration process (1.3) is generally referred to as the Ishikawa iteration process in light of Ishikawa [34]. Another iteration process which has been studied extensively in connection with fixed points of pseudocontractive mappings is the following.

Let $K$ be a nonempty convex subset of $E$ and $T: K \rightarrow K$ be a mapping.

The sequence $\left\{x_{n}\right\}$ is defined iteratively by

$$
\left\{\begin{array}{l}
x_{1} \in K, \\
x_{n+1}=\left(1-c_{n}\right) x_{n}+c_{n} T x_{n}
\end{array}\right.
$$

for each $n \geq 1$, where $\left\{c_{n}\right\}$ is a real sequence satisfying the following conditions:

(d) $0 \leq c_{n}<1$

(e) $\lim c_{n}=0$;

(f) $\sum_{n=1}^{\infty} c_{n}=\infty$.

The iteration process (1.4) is generally referred to as the Mann iteration process in light of [36].

In 1995, Liu [37] introduced the iteration process with errors as follows. 
(I-a) The sequence $\left\{x_{n}\right\}$ defined by

$$
\left\{\begin{array}{l}
x_{1} \in K \\
x_{n+1}=\left(1-\alpha_{n}\right) x_{n}+\alpha_{n} T y_{n}+u_{n} \\
y_{n}=\left(1-\beta_{n}\right) x_{n}+\beta_{n} T x_{n}+v_{n}
\end{array}\right.
$$

for each $n \geq 1$, where $\left\{\alpha_{n}\right\},\left\{\beta_{n}\right\}$ are the sequences in $[0,1]$ satisfying appropriate conditions and $\sum\left\|u_{n}\right\|<\infty, \sum\left\|v_{n}\right\|<\infty$, is called the Ishikawa iteration process with errors.

(I-b) The sequence $\left\{x_{n}\right\}$ defined by

$$
\left\{\begin{array}{l}
x_{1} \in K \\
x_{n+1}=\left(1-\alpha_{n}\right) x_{n}+\alpha_{n} T x_{n}+u_{n}
\end{array}\right.
$$

for each $n \geq 1$, where $\left\{\alpha_{n}\right\}$ is a sequence in $[0,1]$ satisfying appropriate conditions and $\sum\left\|u_{n}\right\|<\infty$, is called the Mann iteration process with errors.

While it is known that the consideration of error terms in the iterative processes (1.5), (1.6) is an important part of the theory, it is also clear that the iterative processes with errors introduced by Liu in (I-a) and (I-b) are unsatisfactory. The occurrence of errors is random so the conditions imposed on the error terms in (I-a) and (I-b), which imply, in particular, that they tend to zero as $n$ tends to infinity, are unreasonable. In 1997, Xu [32] introduced the following more satisfactory definitions.

(I-c) The sequence $\left\{x_{n}\right\}$ defined iteratively by

$$
\left\{\begin{array}{l}
x_{1} \in K, \\
x_{n+1}=a_{n} x_{n}+b_{n} T y_{n}+c_{n} u_{n}, \\
y_{n}=a_{n}^{\prime} x_{n}+b_{n}^{\prime} T x_{n}+c_{n}^{\prime} v_{n}
\end{array}\right.
$$

for each $n \geq 1$, where $\left\{u_{n}\right\},\left\{v_{n}\right\}$ are the bounded sequences in $K$ and $\left\{a_{n}\right\},\left\{b_{n}\right\},\left\{c_{n}\right\},\left\{a_{n}^{\prime}\right\}$, $\left\{b_{n}^{\prime}\right\}$ and $\left\{c_{n}^{\prime}\right\}$ are the sequences in $[0,1]$ such that $a_{n}+b_{n}+c_{n}=a_{n}^{\prime}+b_{n}^{\prime}+c_{n}^{\prime}=1$ for each $n \geq 1$, is called the Ishikawa iteration sequence with errors in the sense of $\mathrm{Xu}$.

(I-d) If, with the same notations and definitions as in (I-c), $b_{n}^{\prime}=c_{n}^{\prime}=0$ for each $n \geq 1$, then the sequence $\left\{x_{n}\right\}$ now defined by

$$
\left\{\begin{array}{l}
x_{1} \in K \\
x_{n+1}=a_{n} x_{n}+b_{n} T x_{n}+c_{n} u_{n}
\end{array}\right.
$$

for each $n \geq 1$ is called the Mann iteration sequence with errors in the sense of Xu.

We remark that if $K$ is bounded (as is generally the case), then the error terms $u_{n}, v_{n}$ are arbitrary in $K$.

In [11], Chidume and Chika Moore proved the following theorem.

Theorem 1.2 Let $K$ be a compact convex subset of a real Hilbert space $H$ and $T: K \rightarrow K$ be a continuous hemicontractive mapping. Let $\left\{a_{n}\right\},\left\{b_{n}\right\},\left\{c_{n}\right\},\left\{a_{n}^{\prime}\right\},\left\{b_{n}^{\prime}\right\}$ and $\left\{c_{n}^{\prime}\right\}$ be the real sequences in $[0,1]$ satisfying the following conditions:

(g) $a_{n}+b_{n}+c_{n}=1=a_{n}^{\prime}+b_{n}^{\prime}+c_{n}^{\prime}$; 
(h) $\lim b_{n}=\lim b_{n}^{\prime}=0$;

(i) $\sum c_{n}<\infty ; \sum c_{n}^{\prime}<\infty$;

(j) $\sum \alpha_{n} \beta_{n}=\infty$ and $\sum \alpha_{n} \beta_{n} \delta_{n}<\infty$, where $\delta_{n}:=\left\|T x_{n}-T y_{n}\right\|^{2}$;

(k) $0 \leq \alpha_{n} \leq \beta_{n}<1$ for each $n \geq 1$, where $\alpha_{n}:=b_{n}+c_{n}$ and $\beta_{n}:=b_{n}^{\prime}+c_{n}^{\prime}$.

For arbitrary $x_{1} \in K$, define the sequence $\left\{x_{n}\right\}$ iteratively by

$$
\left\{\begin{array}{l}
x_{n+1}=a_{n} x_{n}+b_{n} T y_{n}+c_{n} u_{n}, \\
y_{n}=a_{n}^{\prime} x_{n}+b_{n}^{\prime} T x_{n}+c_{n}^{\prime} v_{n}
\end{array}\right.
$$

for each $n \geq 1$, where $\left\{u_{n}\right\}$ and $\left\{v_{n}\right\}$ are the arbitrary sequences in $K$. Then $\left\{x_{n}\right\}$ converges strongly to a fixed point of $T$.

They also gave the following remark in [11].

Remark 1.1 (1) In connection with the iterative approximation of fixed points of pseudocontractive mappings, the following question is still open.

Does the Mann iteration process always converge for continuous pseudocontractive mappings or for even Lipschitz pseudocontractive mappings?

(2) Let $E$ be a Banach space and $K$ be a nonempty compact convex subset of $E$. Let $T: K \rightarrow K$ be a Lipschitz pseudocontractive mapping. Under this setting, even for $E=H$, a Hilbert space, the answer to the above question is not known. There is, however, an example [34] of a discontinuous pseudocontractive mapping $T$ with a unique fixed point for which the Mann iteration process does not always converge to the fixed point of $T$.

Let $H$ be the complex plane and $K:=\{z \in H:|z| \leq 1\}$. Define a mapping $T: K \rightarrow K$ by

$$
T\left(r e^{i \theta}\right)= \begin{cases}2 r e^{i\left(\theta+\frac{\pi}{3}\right)} & \text { for } 0 \leq r \leq \frac{1}{2} \\ e^{i\left(\theta+\frac{2 \pi}{3}\right)} & \text { for } \frac{1}{2}<r \leq 1\end{cases}
$$

Then zero is the only fixed point of $T$. It is shown in [20] that $T$ is pseudocontractive and, with $c_{n}=\frac{1}{n+1}$, the sequence $\left\{z_{n}\right\}$ defined by

$$
\left\{\begin{array}{l}
z_{0} \in K \\
z_{n+1}=\left(1-c_{n}\right) z_{n}+c_{n} T z_{n}
\end{array}\right.
$$

for each $n \geq 1$ does not converge to zero. Since the $T$ in this example is not continuous, the above question remains open.

In [14], Chidume and Mutangadura provide an example of a Lipschitz pseudocontractive mapping with a unique fixed point for which the Mann iteration sequence failed to converge and they stated that 'This resolves a long standing open problem. However, in [38, 39], Rafiq provided affirmative answers to the above questions (see also [40]) and proved the following result.

Theorem 1.3 Let $K$ be a compact convex subset of a real Hilbert space $H$ and $T: K \rightarrow K$ be a continuous hemicontractive mapping. Let $\left\{\alpha_{n}\right\}$ be a real sequence in $[0,1]$ satisfying 
$\left\{\alpha_{n}\right\} \subset[\delta, 1-\delta]$ for some $\delta \in(0,1)$. For arbitrary $x_{0} \in K$, define the sequence $\left\{x_{n}\right\}$ by

$$
x_{n}=\alpha_{n} x_{n-1}+\left(1-\alpha_{n}\right) T x_{n}
$$

for each $n \geq 1$. Then $\left\{x_{n}\right\}$ converges strongly to a fixed point of $T$.

The purpose of this paper is to introduce the following Mann-type implicit iteration process associated with a family of continuous hemicontractive mappings to have a strong convergence in the setting of Hilbert spaces.

Let $K$ be a closed convex subset of a real normed space $H$ and $T_{i}: K \rightarrow K, i=1,2, \ldots, k$ be a family of mappings. Then we define the sequence $\left\{x_{n}\right\}$ in the following way:

$$
\left\{\begin{array}{l}
x_{0} \in K, \\
x_{n}=\alpha_{n} x_{n-1}+\sum_{i=1}^{k} \beta_{n}^{i} T_{i} x_{n}
\end{array}\right.
$$

for each $n \geq 1$, where $\alpha_{n}, \beta_{n}^{i} \in[0,1], i=1,2, \ldots, k$, are such that $\alpha_{n}+\sum_{i=1}^{k} \beta_{n}^{i}=1$ and some appropriate conditions hold.

\section{Main results}

In the sequel, we will use following results.

Lemma 2.1 [29] Suppose that $\left\{\rho_{n}\right\},\left\{\sigma_{n}\right\}$ are two sequences of nonnegative numbers such that, for some real number $N_{0} \geq 1$,

$$
\rho_{n+1} \leq \rho_{n}+\sigma_{n}
$$

for all $n \geq N_{0}$. Then we have the following:

(1) If $\sum \sigma_{n}<\infty$, then $\lim \rho_{n}$ exists.

(2) If $\sum \sigma_{n}<\infty$ and $\left\{\rho_{n}\right\}$ has a subsequence converging to zero, then $\lim \rho_{n}=0$.

Lemma 2.2 [31] For all $x, y \in H$ and $\lambda \in[0,1]$, the following well-known identity holds:

$$
\|(1-\lambda) x+\lambda y\|^{2}=(1-\lambda)\|x\|^{2}+\lambda\|y\|^{2}-\lambda(1-\lambda)\|x-y\|^{2} .
$$

Now, we prove our main results.

Lemma 2.3 Let $H$ be a Hilbert space. Then, for all $x, x_{i} \in H, i=1,2, \ldots, k$,

$$
\begin{aligned}
\left\|\alpha x+\sum_{i=1}^{k} \beta^{i} x_{i}\right\|^{2}= & \alpha\|x\|^{2}+\sum_{i=1}^{k} \beta^{i}\left\|x_{i}\right\|^{2}-\sum_{i=1}^{k} \alpha \beta^{i}\left\|x_{i}-x\right\|^{2} \\
& -\sum_{\substack{i, j=1 \\
i \neq j}}^{k} \beta^{i} \beta^{j}\left\|x_{i}-x_{j}\right\|^{2},
\end{aligned}
$$

where $\alpha, \beta^{i} \in[0,1], i=1,2, \ldots, k$, and $\alpha+\sum_{i=1}^{k} \beta^{i}=1$. 
Proof For any $x_{i} \in H, i=1,2, \ldots, k$, it can be easily seen that

$$
\left\|\sum_{i=1}^{k} x_{i}\right\|^{2}=\sum_{i=1}^{k}\left\|x_{i}\right\|^{2}+2 \sum_{\substack{i, j=1 \\ i \neq j}}^{k} \operatorname{Re}\left\langle x_{i}, x_{j}\right\rangle .
$$

Consider the following:

$$
\begin{aligned}
\left\|\alpha x+\sum_{i=1}^{k} \beta^{i} x_{i}\right\|^{2}= & \left\|\left(1-\sum_{i=1}^{k} \beta^{i}\right) x+\sum_{i=1}^{k} \beta^{i} x_{i}\right\|^{2} \\
= & \left\|x+\sum_{i=1}^{k} \beta^{i}\left(x_{i}-x\right)\right\|^{2} \\
= & \|x\|^{2}+\sum_{i=1}^{k} \beta^{i^{2}}\left\|x_{i}-x\right\|^{2}+2 \sum_{i=1}^{k} \beta^{i} \operatorname{Re}\left\langle x_{i}-x, x\right\rangle \\
& +2 \sum_{\substack{i, j=1 \\
i \neq j}}^{k} \beta^{i} \beta^{j} \operatorname{Re}\left\langle x_{i}-x, x_{j}-x\right\rangle .
\end{aligned}
$$

For all $i, j=1,2, \ldots, k$, we have

$$
2 \operatorname{Re}\left\langle x_{i}-x, x\right\rangle=\left\|x_{i}\right\|^{2}-\left\|x_{i}-x\right\|^{2}-\|x\|^{2},
$$

and

$$
2 \operatorname{Re}\left\langle x_{i}-x, x_{j}-x\right\rangle=-\left\|x_{i}-x_{j}\right\|^{2}+\left\|x_{i}-x\right\|^{2}+\left\|x_{j}-x\right\|^{2} .
$$

Substituting (2.4) and (2.5) in (2.3), we get

$$
\begin{aligned}
& \left\|\alpha x+\sum_{i=1}^{k} \beta^{i} x_{i}\right\|^{2} \\
& =\alpha\|x\|^{2}+\sum_{i=1}^{k} \beta^{i}\left\|x_{i}\right\|^{2}-\sum_{\substack{i, j=1 \\
i \neq j}}^{k} \beta^{i} \beta^{j}\left\|x_{i}-x_{j}\right\|^{2}-\sum_{i=1}^{k} \beta^{i}\left(1-\beta^{i}\right)\left\|x_{i}-x\right\|^{2} \\
& +\sum_{\substack{i, j=1 \\
i \neq j}}^{k} \beta^{i} \beta^{j}\left(\left\|x_{i}-x\right\|^{2}+\left\|x_{j}-x\right\|^{2}\right) \\
& =\alpha\|x\|^{2}+\sum_{i=1}^{k} \beta^{i}\left\|x_{i}\right\|^{2}-\sum_{\substack{i, j=1 \\
i \neq j}}^{k} \beta^{i} \beta^{j}\left\|x_{i}-x_{j}\right\|^{2}-\sum_{i=1}^{k}\left(1-\sum_{j=1}^{k} \beta^{j} \beta^{i}\left\|x_{i}-x\right\|^{2}\right. \\
& =\alpha\|x\|^{2}+\sum_{i=1}^{k} \beta^{i}\left\|x_{i}\right\|^{2}-\sum_{\substack{i, j=1 \\
i \neq j}}^{k} \beta^{i} \beta^{j}\left\|x_{i}-x_{j}\right\|^{2}-\sum_{i=1}^{k} \alpha \beta^{i}\left\|x_{i}-x\right\|^{2} .
\end{aligned}
$$

This completes the proof. 
Remark 2.1 Lemma 2.2 is now the special case of our result.

Theorem 2.1 Let $K$ be a compact convex subset of a real Hilbert space $H$ and $T_{i}: K \rightarrow K$, $i=1,2, \ldots, k$, be a family of continuous hemicontractive mappings. Let $\alpha_{n}, \beta_{n}^{i} \in[0,1]$ be such that $\alpha_{n}+\sum_{i=1}^{k} \beta_{n}^{i}=1$ and satisfying $\left\{\alpha_{n}\right\}, \beta_{n}^{i} \subset[\delta, 1-\delta]$ for some $\delta \in(0,1), i=1,2, \ldots, k$.

Then, for arbitrary $x_{0} \in K$, the sequence $\left\{x_{n}\right\}$ defined by (1.9) converges strongly to a common fixed point in $\bigcap_{i=1}^{k} F\left(T_{i}\right) \neq \emptyset$.

Proof Let $x^{*} \in \bigcap_{i=1}^{k} F\left(T_{i}\right)$. Using the fact that $T_{i}, i=1,2, \ldots, k$ are hemicontractive, we obtain

$$
\left\|T_{i} x_{n}-x^{*}\right\|^{2} \leq\left\|x_{n}-x^{*}\right\|^{2}+\left\|x_{n}-T_{i} x_{n}\right\|^{2} .
$$

With the help of (1.9), Lemma 2.3 and (2.6), we obtain the following estimates:

$$
\begin{aligned}
\left\|x_{n}-x^{*}\right\|^{2}= & \left\|\alpha_{n} x_{n-1}+\sum_{i=1}^{k} \beta_{n}^{i} T_{i} x_{n}-x^{*}\right\|^{2} \\
= & \left\|\alpha_{n}\left(x_{n-1}-x^{*}\right)+\sum_{i=1}^{k} \beta_{n}^{i}\left(T_{i} x_{n}-x^{*}\right)\right\|^{2} \\
= & \alpha_{n}\left\|x_{n-1}-x^{*}\right\|^{2}+\sum_{i=1}^{k} \beta_{n}^{i}\left\|T_{i} x_{n}-x^{*}\right\|^{2}-\sum_{i=1}^{k} \alpha_{n} \beta_{n}^{i}\left\|x_{n-1}-T_{i} x_{n}\right\|^{2} \\
& -\sum_{\substack{i, j=1 \\
i \neq j}}^{k} \beta_{n}^{i} \beta_{n}^{j}\left\|T_{i} x_{n}-T_{j} x_{n}\right\|^{2} \\
\leq & \alpha_{n}\left\|x_{n-1}-x^{*}\right\|^{2}+\sum_{i=1}^{k} \beta_{n}^{i}\left\|T_{i} x_{n}-x^{*}\right\|^{2}-\sum_{i=1}^{k} \alpha_{n} \beta_{n}^{i}\left\|x_{n-1}-T_{i} x_{n}\right\|^{2} .
\end{aligned}
$$

Substituting (2.6) in (2.7), we get

$$
\begin{aligned}
& \left\|x_{n}-x^{*}\right\|^{2} \\
& \leq \alpha_{n}\left\|x_{n-1}-x^{*}\right\|^{2}+\sum_{i=1}^{k} \beta_{n}^{i}\left\|x_{n}-x^{*}\right\|^{2}+\sum_{i=1}^{k} \beta_{n}^{i}\left\|x_{n}-T_{i} x_{n}\right\|^{2} \\
& \quad-\sum_{i=1}^{k} \alpha_{n} \beta_{n}^{i}\left\|x_{n-1}-T_{i} x_{n}\right\|^{2} .
\end{aligned}
$$

Also, we have

$$
\begin{aligned}
\left\|x_{n}-T_{i} x_{n}\right\|^{2} & =\left\|\alpha_{n} x_{n-1}+\sum_{i=1}^{k} \beta_{n}^{i} T_{i} x_{n}-T_{i} x_{n}\right\|^{2} \\
& =\alpha_{n}^{2}\left\|x_{n-1}-T_{i} x_{n}\right\|^{2} .
\end{aligned}
$$


Substituting (2.9) in (2.8), we get

$$
\left\|x_{n}-x^{*}\right\|^{2} \leq \alpha_{n}\left\|x_{n-1}-x^{*}\right\|^{2}+\sum_{i=1}^{k} \beta_{n}^{i}\left\|x_{n}-x^{*}\right\|^{2}-\sum_{i=1}^{k} \alpha_{n}\left(1-\alpha_{n}\right) \beta_{n}^{i}\left\|x_{n-1}-T_{i} x_{n}\right\|^{2},
$$

which implies that

$$
\left\|x_{n}-x^{*}\right\|^{2} \leq\left\|x_{n-1}-x^{*}\right\|^{2}-\sum_{i=1}^{k}\left(1-\alpha_{n}\right) \beta_{n}^{i}\left\|x_{n-1}-T_{i} x_{n}\right\|^{2}
$$

Thus, from the condition $\left\{\alpha_{n}\right\}, \beta_{n}^{i} \subset[\delta, 1-\delta]$ for some $\delta \in(0,1), i=1,2, \ldots, k$, we obtain

$$
\left\|x_{n}-x^{*}\right\|^{2} \leq\left\|x_{n-1}-x^{*}\right\|^{2}-\delta(1-\delta) \sum_{i=1}^{k}\left\|x_{n-1}-T_{i} x_{n}\right\|^{2}
$$

for all fixed points $x^{*} \in \bigcap_{i=1}^{k} F\left(T_{i}\right)$. Moreover, we have

$$
\delta(1-\delta) \sum_{i=1}^{k}\left\|x_{n-1}-T_{i} x_{n}\right\|^{2} \leq\left\|x_{n-1}-x^{*}\right\|^{2}-\left\|x_{n}-x^{*}\right\|^{2},
$$

and thus, for all $i=1,2, \ldots, k$,

$$
\begin{aligned}
\delta(1-\delta) \sum_{j=1}^{\infty}\left\|x_{j-1}-T_{i} x_{j}\right\|^{2} & \leq \sum_{j=1}^{\infty}\left(\left\|x_{j-1}-x^{*}\right\|^{2}-\left\|x_{j}-x^{*}\right\|^{2}\right) \\
& =\left\|x_{0}-x^{*}\right\|^{2} .
\end{aligned}
$$

Hence, for all $i=1,2, \ldots, k$, we obtain

$$
\sum_{j=1}^{\infty}\left\|x_{j-1}-T_{i} x_{j}\right\|^{2}<\infty
$$

for each $i=1,2, \ldots, k$, which implies that

$$
\lim _{n \rightarrow \infty}\left\|x_{n-1}-T_{i} x_{n}\right\|=0
$$

for each $i=1,2, \ldots, k$. From (2.9), it further implies that

$$
\lim _{n \rightarrow \infty}\left\|x_{n}-T_{i} x_{n}\right\|=0
$$

By the compactness of $K$, this immediately implies that there is a subsequence $\left\{x_{n_{j}}\right\}$ of $\left\{x_{n}\right\}$ which converges to a common fixed point of $\bigcap_{i=1}^{k} F\left(T_{i}\right)$, say $y^{*}$. Since (2.10) holds for all fixed points of $\bigcap_{i=1}^{k} F\left(T_{i}\right)$, we have

$$
\left\|x_{n}-y^{*}\right\|^{2} \leq\left\|x_{n-1}-y^{*}\right\|^{2}-\delta(1-\delta) \sum_{i=1}^{k} \beta_{n}^{i}\left\|x_{n-1}-T_{i} x_{n}\right\|^{2}
$$


and, in view of (2.11) and Lemma 2.1, we conclude that $\left\|x_{n}-y^{*}\right\| \rightarrow 0$ as $n \rightarrow \infty$, that is, $x_{n} \rightarrow y^{*}$ as $n \rightarrow \infty$. This completes the proof.

Theorem 2.2 Let $H, K, T_{i}, i=1,2, \ldots, k$, be as in Theorem 2.1 and $\alpha_{n}, \beta_{n}^{i} \in[0,1]$ be such that $\alpha_{n}+\sum_{i=1}^{k} \beta_{n}^{i}=1$ and satisfying $\left\{\alpha_{n}\right\}, \beta_{n}^{i} \subset[\delta, 1-\delta]$ for some $\delta \in(0,1), i=1,2, \ldots, k$.

If $P_{K}: H \rightarrow K$ is the projection operator of $H$ onto $K$, then the sequence $\left\{x_{n}\right\}$ defined iteratively by

$$
x_{n}=P_{K}\left(\alpha_{n} x_{n-1}+\sum_{i=1}^{k} \beta_{n}^{i} T_{i} x_{n}\right)
$$

for each $n \geq 0$ converges strongly to a common fixed point in $\bigcap_{i=1}^{k} F\left(T_{i}\right) \neq \emptyset$.

Proof The mapping $P_{K}$ is nonexpansive (see [2]) and $K$ is a Chebyshev subset of $H$ and so $P_{K}$ is a single-valued mapping. Hence, we have the following estimate:

$$
\begin{aligned}
\left\|x_{n}-x^{*}\right\|^{2}= & \left\|P_{K}\left(\alpha_{n} x_{n-1}+\sum_{i=1}^{k} \beta_{n}^{i} T_{i} x_{n}\right)-P_{K} x^{*}\right\|^{2} \\
\leq & \left\|\alpha_{n} x_{n-1}+\sum_{i=1}^{k} \beta_{n}^{i} T_{i} x_{n}-x^{*}\right\|^{2} \\
= & \left\|\alpha_{n}\left(x_{n-1}-x^{*}\right)+\sum_{i=1}^{k} \beta_{n}^{i}\left(T_{i} x_{n}-x^{*}\right)\right\|^{2} \\
\leq & \alpha_{n}\left\|x_{n-1}-x^{*}\right\|^{2}+\sum_{i=1}^{k} \beta_{n}^{i}\left\|x_{n}-x^{*}\right\|^{2} \\
& -\sum_{i=1}^{k} \alpha_{n}\left(1-\alpha_{n}\right) \beta_{n}^{i}\left\|x_{n-1}-T_{i} x_{n}\right\|^{2},
\end{aligned}
$$

which implies that

$$
\left\|x_{n}-x^{*}\right\|^{2} \leq\left\|x_{n-1}-x^{*}\right\|^{2}-\sum_{i=1}^{k}\left(1-\alpha_{n}\right) \beta_{n}^{i}\left\|x_{n-1}-T_{i} x_{n}\right\|^{2}
$$

The set $K \cup T(K)$ is compact and so the sequence $\left\{\left\|x_{n}-T_{i} x_{n}\right\|\right\}$ is bounded. The rest of the argument follows exactly as in the proof of Theorem 2.1. This completes the proof.

Theorem 2.3 Let $K$ be a compact convex subset of a real Hilbert space $H$ and $T_{i}: K \rightarrow K$, $i=1,2, \ldots, k$, be a family of Lipschitz hemicontractive mappings. Let $\alpha_{n}, \beta_{n}^{i} \in[0,1]$ be such that $\alpha_{n}+\sum_{i=1}^{k} \beta_{n}^{i}=1$ and satisfying $\left\{\alpha_{n}\right\}, \beta_{n}^{i} \subset[\delta, 1-\delta]$ for some $\delta \in(0,1), i=1,2, \ldots, k$.

Then, for arbitrary $x_{0} \in K$, the sequence $\left\{x_{n}\right\}$ defined by (1.9) converges strongly to a common fixed point in $\bigcap_{i=1}^{k} F\left(T_{i}\right) \neq \emptyset$.

Theorem 2.4 Let $H, K, T_{i}, i=1,2, \ldots, k$, be as in Theorem 2.3 and $\alpha_{n}, \beta_{n}^{i} \in[0,1]$ be such that $\alpha_{n}+\sum_{i=1}^{k} \beta_{n}^{i}=1$ and satisfying $\left\{\alpha_{n}\right\}, \beta_{n}^{i} \subset[\delta, 1-\delta]$ for some $\delta \in(0,1), i=1,2, \ldots, k$. 
If $P_{K}: H \rightarrow K$ is the projection operator of $H$ onto $K$, then the sequence $\left\{x_{n}\right\}$ defined iteratively by

$$
x_{n}=P_{K}\left(\alpha_{n} x_{n-1}+\sum_{i=1}^{k} \beta_{n}^{i} T_{i} x_{n}\right)
$$

for each $n \geq 1$ converges strongly to a common fixed point in $\bigcap_{i=1}^{k} F\left(T_{i}\right) \neq \emptyset$.

Example For $k=2$, we can choose the following control parameters: $\alpha_{n}=\frac{1}{4}-\frac{1}{(n+2)^{2}}, \beta_{n}^{1}=\frac{1}{4}$ and $\beta_{n}^{2}=\frac{1}{2}+\frac{1}{(n+2)^{2}}$.

\section{Competing interests}

The authors declare that they have no competing interests.

\section{Authors' contributions}

All authors contributed equally and significantly in writing this article. All authors read and approved the final manuscript.

\section{Author details}

${ }^{1}$ Department of Mathematics, King Abdulaziz University, P.O. Box 80203, Jeddah, 21589, Saudi Arabia. ${ }^{2}$ Faculty of Mechanical Engineering, University of Belgrade, Kraljice Marije 16, Belgrade, Serbia. ${ }^{3}$ Department of Mathematics Education and RINS, Gyeongsang National University, Jinju, 660-701, Korea. ${ }^{4}$ Department of Mathematics Education, Kyungnam University, Masan, Kyungnam 631-701, Korea. ${ }^{5}$ Hajvery University, 43-52 Industrial Area Gulberg-III, Lahore, Pakistan.

\section{Acknowledgements}

We are grateful to the editor and the referees for their valuable suggestions for the improvement of this manuscript. The first author gratefully acknowledges the support from the Deanship of Scientific Research (DSR) at King Abdulaziz University (KAU) during this research.

The second author is supported by the Ministry of Science, Technology and Development, Republic of Serbia. The third author was supported by the Basic Science Research Program through the National Research Foundation of Korea (NRF) funded by the Ministry of Education, Science and Technology (Grant Number: 2012-0008170).

Received: 1 September 2012 Accepted: 24 January 2013 Published: 7 February 2013

\section{References}

1. Browder, FE: Nonlinear operators and nonlinear equations of evolution in Banach spaces. In: Proc. of Symposia in Pure Math., Vol. XVIII, Part 2 (1976)

2. Browder, FE, Petryshyn, WV: Construction of fixed points of nonlinear mappings in Hilbert spaces. J. Math. Anal. Appl. 20, 197-228 (1967)

3. Schu, J: On a theorem of C.E. Chidume concerning the iterative approximation of fixed points. Math. Nachr. 153 , 313-319 (1991)

4. Schu, J: Iterative construction of fixed points of asymptotically nonexpansive mappings. J. Math. Anal. Appl. 158, 407-413 (1991)

5. Xu, ZB, Roach, GF A necessary and sufficient condition for convergence of steepest descent approximation to accretive operator equations. J. Math. Anal. Appl. 167, 340-354 (1992)

6. Qihou, L: The convergence theorems of the sequence of Ishikawa iterates for hemicontractive mappings. J. Math Anal. Appl. 148, 55-62 (1990)

7. Chidume, CE: Iterative approximation of Lipschitz strictly pseudocontractive mappings. Proc. Am. Math. Soc. 99 283-288 (1987)

8. Chidume, CE: Approximation of fixed points of strongly pseudocontractive mappings. Proc. Am. Math. Soc. 120 545-551 (1994)

9. Chidume, CE: Global iteration schemes for strongly pseudocontractive maps. Proc. Am. Math. Soc. 126, 2641-2649 (1998)

10. Chidume, CE: Iterative solution of nonlinear equations of strongly accretive type. Math. Nachr. 189, 49-60 (1998)

11. Chidume, CE, Moore, C: Fixed point iteration for pseudocontractive maps. Proc. Am. Math. Soc. 127, 1163-1170 (1999)

12. Chidume, CE, Osilike, MO: Ishikawa iteration process for nonlinear Lipschitz strongly accretive mappings. J. Math. Anal. Appl. 192, 727-741 (1995)

13. Chidume, CE, Osilike, MO: Nonlinear accretive and pseudocontractive operator equations in Banach spaces. Nonlinear Anal. 31, 779-789 (1998)

14. Chidume, CE, Mutangadura, SA: An example on the Mann iteration method for Lipschitz pseudocontractions. Proc. Am. Math. Soc. 129, 2359-2363 (2001)

15. Cho, YJ, Kang, SM, Qin, X: Strong convergence of an implicit iterative process for an infinite family of strict pseudocontractions. Bull. Korean Math. Soc. 47, 1259-1268 (2010) 
16. Cho, YJ, Kim, JK, Lan, HY: Three step procedure with errors for generalized asymptotically quasi-nonexpansive mappings in Banach spaces. Taiwan. J. Math. 12, 2155-2178 (2008)

17. Crandall, MG, Pazy, A: On the range of accretive operators. Isr. J. Math. 27, 235-246 (1977)

18. Deng, L: On Chidume's open problems. J. Math. Anal. Appl. 174(2), 441-449 (1993)

19. Deng, L: Iteration process for nonlinear Lipschitzian strongly accretive mappings in $L_{p}$ spaces. J. Math. Anal. Appl. 188 128-140 (1994)

20. Deng, L, Ding, XP: Iterative approximation of Lipschitz strictly pseudocontractive mappings in uniformly smooth Banach spaces. Nonlinear Anal. 24, 981-987 (1995)

21. Hicks, TL, Kubicek, JR: On the Mann iteration process in Hilbert space. J. Math. Anal. Appl. 59, 498-504 (1977)

22. Reich, S: Constructing zeros of accretive operators, II. Appl. Anal. 9, 159-163 (1979)

23. Reich, S: Weak convergence theorems for nonexpansive mappings in Banach spaces. J. Math. Anal. Appl. 67, 274-276 (1979)

24. Reich, S: Strong convergence theorems for resolvents of accretive operators in Banach spaces. J. Math. Anal. Appl. 75 287-292 (1980)

25. Rhoades, BE: Comments on two fixed point iteration procedures. J. Math. Anal. Appl. 56, 741-750 (1976)

26. Schu, J: Iterative construction of fixed points of strictly pseudocontractive mappings. Appl. Anal. 40, 67-72 (1991)

27. Song, Y, Cho, YJ: Some notes on ishikawa iteration for multi-valued mappings. Bull. Korean Math. Soc. 48, 575-584 (2011)

28. Suantai, S, Cho, YJ, Cholamjiak, P: Composite iterative schemes for maximal monotone operators in reflexive Banach spaces. Fixed Point Theory Appl. 2011, Article ID 7 (2011)

29. Tan, KK, Xu, HK: Approximating fixed points of nonexpansive mappings by the ishikawa iteration process. J. Math Anal. Appl. 178, 301-308 (1993)

30. Weng, XL: Fixed point iteration for local strictly pseudocontractive mappings. Proc. Am. Math. Soc. 113, 727-731 (1991)

31. Xu, HK: Inequality in Banach spaces with applications. Nonlinear Anal. 16, 1127-1138 (1991)

32. Xu, Y: Ishikawa and Mann iterative processes with errors for nonlinear strongly accretive operator equations. J. Math. Anal. Appl. 224, 91-101 (1998)

33. Yao, Y, Cho, YJ: A strong convergence of a modified Krasnoselskii-Mann method for non-expansive mappings in Hilbert spaces. Math. Model. Anal. 15, 265-274 (2010)

34. Ishikawa, S: Fixed point by a new iteration method. Proc. Am. Math. Soc. 4(1), 147-150 (1974)

35. Qihou, L: Convergence theorems of the sequence of iterates for asymptotically demicontractive and hemicontractive mappings. Nonlinear Anal. 26, 1835-1842 (1996)

36. Mann, WR: Mean value methods in iteration. Proc. Am. Math. Soc. 4, 506-610 (1953)

37. Liu, LS: Ishikawa and Mann iteration process with errors for nonlinear strongly accretive mappings in Banach spaces. J. Math. Anal. Appl. 194, 114-125 (1995)

38. Rafiq, A: On Mann iteration in Hilbert spaces. Nonlinear Anal. 66, 2230-2236 (2007)

39. Rafiq, A: Implicit fixed point iterations for pseudocontractive mappings. Kodai Math. J. 32, 146-158 (2009)

40. Ćirić, LB, Rafiq, A, Cakić, N, Ume, JS: Implicit Mann fixed point iterations for pseudo-contractive mappings. Appl. Math Lett. 22, 581-584 (2009)

doi:10.1186/1029-242X-2013-41

Cite this article as: Hussain et al.: On Mann-type iteration method for a family of hemicontractive mappings in Hilbert spaces. Journal of Inequalities and Applications 2013 2013:41.

\section{Submit your manuscript to a SpringerOpen ${ }^{\circ}$ journal and benefit from:}

- Convenient online submission

Rigorous peer review

- Immediate publication on acceptance

- Open access: articles freely available online

- High visibility within the field

- Retaining the copyright to your article 